\title{
EXPERIÊNCIAS URBANAS E MEMÓRIAS EM MÃOS DE CAVALO, DE DANIEL GALERA
}

\author{
Caio Silva Carvalho ${ }^{1}$ \\ Silvana Maria Pantoja dos Santos ${ }^{2}$
}

\begin{abstract}
RESUMO: O espaço literário não é meramente um elemento que completa a narrativa, mas algo dotado de complexidades que completa a identidade dos personagens, bem como o significado do enredo. A memória, por sua vez, se encarrega de guardar as emoções, sentimentos, particularidades dos personagens. Diante disso, o presente trabalho objetiva analisar a relação entre memória e experiência urbana na obra Mãos de Cavalo, do escritor Daniel Galera, a partir dos lugares de referência. Temos como referências básicas os seguintes pressupostos teóricos: no que concerne à memória, adotamos o pensamento de Maurice Halbwachs (1990) e Ecléa Bosi (2003); quanto ao espaço, amparamo-nos na visão de Osmar Lins (1976) e Santos; Oliveira (2001). Assim, o entrelace entre a memória dos personagens da trama com os espaços de vivências suscita a valorização dos lugares da cidade que guardam histórias individuais e coletivas.
\end{abstract}

PALAVRAS-CHAVE: Memória; Espaço; Literatura; Daniel Galera.

\section{INTRODUÇÃO}

O espaço literário, ao longo da historiografia literária, era comumente definido como um mero pano de fundo das cenas, servindo apenas de complemento aos demais elementos de uma determinada narrativa, bem como a um aspecto estritamente geográfico. Essa realidade foi mudando gradativamente, graças à intensificação de estudos nessa linha, a partir dos anos 1960 do século $\mathrm{XX}$.

Atualmente são muitas as pesquisas relacionadas ao espaço na narrativa literária, especialmente numa ótica de entrelace com a memória do lugar. Diante dessa realidade, entendemos que o espaço literário não está presente nas tramas ao acaso, ele é dotado de peculiaridades possíveis de envolver os personagens, no tocante a sentimentos, percepções e sensações. Ruas, casas, praças não são simplesmente elementos geográficos, mas sim fatos urbanos que completam os sujeitos sociais, e dizem muito sobre eles.

Diante disso, a proposta deste trabalho é analisar os lugares de memória citadina, a partir dos espaços de vivências individuais e coletivos dos

\footnotetext{
${ }^{1}$ Graduando em Letras pela Universidade Estadual do Maranhão/ UEMA Campus Timon/MA. Email: caiocarvalho1980@gmail.com

2 Professora Doutora de Literaturas de Língua Portuguesa - UEMA/UESPI; E do mestrado acadêmico - UEMA/UESPI. Coordenadora do Grupo de Pesquisa Interdisciplinar em Literatura e Linguagem - LITERLI. Email: silvanapantoja3@gmail.com
}

Revista de Letras JUÇARA, Caxias - Maranhão, v. 02, n. 01, p. 129 - 139, jul. 2018|129 
personagens da obra Mãos de Cavalo, do escritor paulista Daniel Galera. A motivação para esta abordagem justifica-se pela expansão urbana, articulada ao progresso, que tem impulsionado alterações ou extinções dos espaços de referência.

Concernente ao espaço na literatura, Santos; Oliveira (2001, p.67) apresentam-nos a seguinte indagação: "É possível ser sem estar?". Essa indagação nos permite refletir à respeito da relação entre os verbos ser e estar, uma relação intrínseca, pois é impossível determinarmos algo/alguém sem levar em conta os elementos que os compõem, sugerindo que alguém que existe está intimamente relacionado ao lugar de atuação. Então, acrescenta-nos Santos; Oliveira:

\begin{abstract}
Assim sendo, se criamos uma personagem ficcional, vamos posicioná-la relativamente a outros elementos do nosso texto. Podemos situá-la fisicamente (criamos um espaço geográfico) temporalmente (criamos um espaço histórico), em relação a outros personagens (determinamos um espaço social) em relação às suas próprias características existenciais (criamos um espaço psicológico), em relação às formas como essa personagem é expressa e se expressa (geramos um espaço de linguagem) e assim por diante. (SANTOS; OLIVIERA, 2001, p. 67-68)
\end{abstract}

Desse modo, a Literatura é repleta de elementos que possuem relações entre si, mas tais relações não estão ligadas, apenas, a uma perspectiva estrutural. São elementos que possuem significados afetivos ou de cunho histórico, social, cultural. Encontramos a fenda em que o espaço entra em cena, posto que busca relacionar o ser e o estar, proporcionando meios de possíveis correlações. Essas são percebidas no momento da leitura, quando nos deparamos com os sentimentos das personagens, a citar: a afetividade com os espaços vivenciados na narrativa. São praças, becos, ruas que não são simples locais de um ambiente urbano, mas sim traços que deixam suas marcas nos moradores do lugar.

A memória, por sua vez, é comumente compreendida como um mecanismo psicológico que permite armazenar diferentes formas de informações, impressões ou experiências. Rememorar a cidade é uma forma de dar sentido a lugares que guardam histórias.

Os espaços articulam-se com a memória dos personagens na trama ficcional, no instante em que os mesmos rememoram vivência e/ou experiência 
em um determinado lugar. Os espaços estão presentes, a fim de servirem de complemento à memória, posto que os lugares em que as experiências acontecem se tornam a parte física da rememoração, visto que "Sempre que somos estimulados a ir ao passado, trazemos de volta lembranças que envolvem pessoas, lugares, coisas, enfim, tudo que marcou afetivamente." (JOSÉ, 2012, p. 42).

\subsection{A memória e a trama ficcional}

A obra Mãos de Cavalo possui notável aclamação desde o seu lançamento, em 2010. A escrita do literato contemporâneo paulista, mas que viveu a maior parte de sua vida em Porto Alegre, está ligada a uma simples e escorreita forma de narrar, mas com capacidade de reflexão existencial. $\mathrm{O}$ autor já recebeu vários prêmios literários, como o Prêmio São Paulo de Literatura, em 2013.

A trama se passa na capital do Rio Grande do Sul, Porto Alegre, em que o narrador rememora seu passado dotado de aventuras e reflexões sobre os fatos. O narrador rememora a cidade de Porto Alegre, ressaltando diversos ambientes, como o Rio Guaíba, Rua da Sombra, Rua Quintino Bocaiuva, Avenida Dr. Nilo Peçanha, Avenida Carlos Gomes.

Em sua estrutura, a obra é articulada em duas partes: Na primeira, o narrador rememora o contexto de sua pequenez, suas aventuras ímpares e suas vivências particulares na companhia de amigos de infância. $\mathrm{Na}$ segunda, o narrador se apropria de lembranças de momentos mais recentes, apresentando um Hermano adulto, cirurgião, remontando a experiência vivida.

Sobre os sentimentos de Hermano, personagem central da tram, que denota uma experiência relacionada aos espaços. Assegura Osmar Lins:

[...] E que também suas recordações e até as visões de um futuro feliz, a vitória, a fortuna, flutuam em algo que, se metricamente ao tempo psicológico, designamos como espaço psicológico não fosse a advertência de Hugh M. Lacey de que aos "denominados eventos mentais (percepções, lembranças, desejos, sensações, experiências) não podemos, em nenhum sentido habitual, contribuir localização espacial". (LINS, 1976, p. 69. Aspas do autor)

As lembranças de um determinado personagem, eventualmente compreendidas pelo tempo psicológico, são revestidas de um dado novo: o 
espaço psicológico, entendido por Lins (1979) como um lugar íntimo e subjetivo onde afloram as emoções. Por meio desse espaço interior, o narrador faz uso de sua memória para ressignificar lugares, a partir de seus sentimentos e sensação, com foco em experiências vividas.

O espaço psicológico pode se relacionar com outros elementos, como a percepção, as lembranças, desejos e emoções. No início da trama, o narrador usa sua impressão para dissertar uma cena:

$\mathrm{Na}$ rua do Canteiro, reduz a velocidade da bicicleta até quase parar e permanece alguns segundos observando a descida de cinco quarteirões que se estende à sua frente como a garganta de um imenso paquiderme. Permanecer assim imóvel sem tocar os pés no chão exige uma técnica muito apurada e uma sintonia irretocável entre ciclista e bicicleta (GALERA, 2010, p. 10)

A percepção do narrador, ligada à vivência de Hermano vai dando forma aos espaços e aos fatos urbanos, que vão sendo modelados pela sua visão na proporção de suas ações. O personagem se apropria do espaço, ressaltando suas particularidades íngremes, usando termos para ilustrar sua percepção, a citar: o termo paquiderme, ao relacionar a formação do ambiente narrado à natureza de animais com pele espessa.

\subsection{A rememoração atrelada aos espaços citadinos}

Em A poética do espaço (1993), Gaston Bachelard (1884-1962) nos traz a concepção de que os espaços de vivências têm o poder de provocar sensações no indivíduo, trazendo a este, imagens mentais que causaram marcas na alma. Corroborando com esse pensamento, Henry Bergson (1999) nos fala à respeito do passado como manifestação interior, preservando lembranças afetivas associadas ao espaço. As ações de Hermano são repletas de cenas que evidenciam sua afeição pelo espaço narrado. Muitas cenas remetem a espaços de memória da cidade, como a descrição do Lago Guaíba:

Atravessa agora as calçadas, de cinco casas em sequência, sem grandes desníveis ou mudanças de terrenos, de modo que o ciclista se sente a vontade para relaxar por alguns segundos, reacomodar a palma das mãos nos manetes, afrouxar a tensão dos joelhos e cotovelos e apreciar rapidamente a vista até que o olhar trave na água do Guaíba lá longe, salpicada do branco das velas dos veleiros. (GALERA, 2010, p. 12) 
A citação evidencia a história da cidade de Porto Alegre ambientada na obra. O narrador nos apresenta tal cidade em sua forma, ao citar a apresentação da sequência de casas. A cena literária nos permite reconhecer o apreço que o personagem nutri pelas casas, bem como pelo Lago Guaíba, fazendo com que haja uma aura de tranquilidade, tal apreciação causa um relaxamento ao protagonista.

As casas, assim como o lago, exercem um tipo de fascínio no personagem, que não somente os percebe, mas também os retoma de acordo com suas emoções e impressões. "Lembrava bem da época em que aquele terreno era um loteamento quase virgem, cada terreno baldio guardando algum segredo - um animal vivo ou morto, vestígios de um misterioso acampamento" (GALERA, 2010, p.123). Hermano, ao fazer menção a um passeio da infância, vai devaneando pelos bairros atravessados pela Rua da Serraria, envolta pela atmosfera que emana dos espaços da urbe, com isso vai dando ênfase a costumes de outrora. O narrador reconhece o significado contido nos espaços antigos, a partir da lembrança que tem dos mesmos.

\subsection{A memória individual e coletiva como marcadores de experiências}

A memória não se limita a um único indivíduo, também pode ser compartilhada, pois os elementos que configuram a memória envolvem traços coletivos, dotados de percepções em comum entre diferentes componentes de determinado grupo.

$\mathrm{Na}$ obra Mãos de cavalo temos um episódio em que a esposa de Hermano, Adri, encontra-se em trabalho de parto cheio de percalços. Quando o parto chega ao fim, as percepções do protagonista vão aflorando:

\footnotetext{
Mais tarde, depois que o bebê já tinha mamado e estava sendo visto pelos familiares do casal pela janela de estufa, descobriu que o parto inteiro tinha durado sete minutos. Para ele tinha parecido sete horas, e semanas depois parecia ter durado um dia inteiro. Quando disse isso pra Adri, ela respondeu que na memória dela parecia que tudo tinha acontecido dentro de poucos segundos. (GALERA, 2010, p. 78)
}

O trecho acima evidencia uma lembrança individual de Hermano e de sua esposa. A memória é defendida por Halbwachs (1990) como relativa a uma intuição sensível e subjetiva, com uma perspectiva de uma lembrança íntima de 
cada indivíduo.

Percebemos que, por mais que a cena esteja apresentada com mais de um personagem, cada um tem uma perspectiva diferente. Em relação ao parto, enquanto um exibe a sensação de demora, a outra o percebe como um ato instantâneo, comprovando a ideia da memória individual.

Há, por outro lado, a memória coletiva. Esta possui características mais abrangentes. Para Halbwachs, a memória coletiva é definitiva como um conjunto de recordações construídas em determinado meio ou grupo, que transcende o individual, passando a ser um eixo socialmente construído: "Se algumas lembranças individuais penetram algumas vezes nela, mudam de figura assim que sejam recolocadas num conjunto que não é mais [aquele da] consciência pessoal." (HALBWACHS, 1990, p. 53-54)

Ecléa Bosi (2003) concorda com o pensamento de Halbwachs (1990) ao asseverar que a memória coletiva traz a marca de determinado grupo. A socióloga ressalta que "Há uma memória coletiva produzida no interior de uma classe/grupo, mas com poder de difusão, que se alimenta de imagens, sentimentos, ideias e valores que dão identidade àquela classe." (BOSI, 2003, p.18).

A memória coletiva se difere da individual em outro quesito: ela sempre está se redefinindo, pois a valorização de um período está intrinsecamente ligada a um grupo não se limitando à percepção emocional de um indivíduo por si, mas trata-se de uma experiência em comum. A cena a seguir nos apresenta um costume das pessoas do convívio de Hermano:

\footnotetext{
Enquanto a cidade inteira aproveitava as férias de verão, para abandonar a capital e desfrutar as delícias da maritimidade, os habitantes da Esplanada tinham o excêntrico hábito de permanecer, reagindo com desdém ou simples indiferença a ideia de viajar para o litoral, convictos de que a enlouquecedora umidade porto-alegrense, os churrascos quase diários, os banhos de mangueira na calçada [...] eram preferíveis às multidões. (GALERA, 2010, p. 79)
}

Percebemos que o narrador reconhece que os moradores da Esplanada compartilham do mesmo sentimento, a preferência da diversão urbana de determinado grupo é o que torna a vivência distinta, comprovando a memória coletiva ressaltada por Halbwachs (1990) e confirmada por Ecléa Bosi (2003).

Os espaços evidenciados na obra estão ligados à parte antiga da cidade, 
esta torna-se guardiã da memória do lugar, logo, são espaços convergentes ao imaginário coletivo, configurados a partir da memória individual. Um único lugar pode contribuir para o surgimento de diferentes sensações. A variação de tais sensações depende do estado de espírito em que se encontra uma personagem ou pelo sentimento que carrega pelo lugar.

Hermano é um conhecedor nato de sua cidade, apegado às diferentes formas cartográficas da capital porto-alegrense, ele descreve os lugares com precisão e emoção.

\begin{abstract}
A faixa é uma avenida asfaltada. O percurso prevê somente uns cinquenta metros sobre a via, até que se possa pegar a rua da Sombra à direita e seguir por ela até o objetivo final, a avenida Guaíba. Cinquenta metros de asfalto lisinho e dócil seriam para um Ciclista Urbano como uma maçã raspada no prato, para comer de colherinha, com açúcar. (GALERA, 2010, p. 13)
\end{abstract}

A imagem poética com a qual Hermano descreve a forma urbana de sua cidade assemelha-se a uma "maçã raspada no prato", aproximando-se de uma conjuntura fácil, deslizante. O narrador demonstra ser conhecedor do lugar e de suas particularidades. Vimos que ele não se limita a conhecer uma rua por sua mera estrutura, mas busca o significado íntimo que o lugar comporta em suas vivências.

O narrador dá destaque a outros espaços que remetem à cartografia da cidade, como: Rua do Canteiro, Avenida Guaíba, Rua da Sombra, Rua Quintino Bocaiuva, avenida Dr. Nilo Peçanha, avenida Carlos Gomes, Via Terceira Perimetral, dentre outros. São imagens que ressignificam espaços de vivências individuais e coletivas, contribuindo para a preservação da memória do lugar.

O espaço literário é configurado a partir de uma carga simbólica, desencadeada pelas interpretações que se tem dele, sendo, em geral, condicionada à percepção dos personagens, o que gera um enlace de sentimentos. Cláudia Barbieri (2009) ressalta que:

A construção espacial da narrativa deixa de ser passiva - enquanto um elemento necessário apenas à contextualização e pano de fundo para os acontecimentos - e passa a ser um agente ativo: o espaço, o lugar como articulador da história. A percepção deste pela personagem e seu percurso dão ao leitor uma maior compreensão da constituição de ambos e ampliam as possibilidades de significação do texto. (BARBIERI, 2009, p. 105) 
A autora defende a ideia de que os espaços deixam de ser passivos, a partir do instante em que são depositadas impressões sobre eles. Na obra Mão de cavalo isso é verificado em várias passagens, como podemos constatar no excerto a seguir:

\begin{abstract}
Ninguém jamais desceria aquela escadaria mais rápido do que ele estava descendo agora. Era impossível. Tinha a impressão de que as rodas nem tocavam o chão. $O$ mundo a seu redor se transformou em um borrão e seus olhos lacrimejavam com o vento. Nos primeiros segundos de descida, percebeu que já não tinha controle da bicicleta. (GALERA, 2010. P. 91)
\end{abstract}

A escadaria é ressignificada pelo olhar do personagem, no instante em que recebe uma carga de impressões, cuja atmosfera da cena é revestida por um tom de aventura e de risco. O fascínio de Hermano pela suntuosidade da escadaria faz com que a torne peculiar, cuja forma denota que surgira desordenada. $O$ personagem aventura-se na frente de seus colegas, fascinado tanto perigo, quanto pela possibilidade da queda.

À medida que as cidades se modernizam e a vida torna-se mais apressada, há uma tendência ao desfavorecimento da memória do lugar. "O contexto social transformara-se em um vazio ou deserto de afinidades para com os valores coletivos; deserto de sensibilidade à memória social, deserto de cordialidade, de convivência interpessoal, de vida humanizada." (SANTOS, 2015, p.226) Nessa perspectiva, Santos (2015) discorre sobre a instabilidade dos espaços, ou da permanência dos mesmos. A dinâmica da cidade acarreta o desgaste dos espaços de memória, contudo a obra literária contribui para o ressignificar, bem como para o fortalecimento da identidade do lugar. $O$ personagem da trama gaúcha lamenta a realidade pautada, ao perceber as alterações impressas em alguns espaços:

\footnotetext{
Uma gigantesca amostra de materiais de construção baratos projetados por uma seita maligna de engenheiros civis e arquitetos lobotomizados. Percorre algumas centenas de metros pela estrada da Serraria e entra na rua do Canteiro." (GALERA, 2010, p.124)
}

Apesar da modernização, o personagem reconhece que os espaços preservam alguns elementos da forma original, deixando sua experiência viva: "as lixeiras de aço enferrujadas, os cachorros da rua roçando focinho com os cachorros presos em casa por grades e coleiras" (GALERA, 2010, p.124). 
Santos (2015 p. 207) assevera que as nomenclaturas dos lugares não surgem de forma aleatória, os nomes dos logradouros possuem ligações com suas origens, trazendo referências sobre o lugar. Em Mãos de Cavalo há menção à Rua da Sombra, que o narrador diz ser "aquele trecho úmido de calçada, sob um teto de copas de árvores que justificam o nome". (GALERA, 2010, p. 15)

Diante do exposto, constatamos que os lugares descritos na obra Mãos de Cavalo, de Daniel Galera, são repletos de significados para a personagem Hermano e se desdobram em lugares de memória, contribuindo para a preservação da memória citadina. Percebemos, também, que os espaços citadinos, bem como seus respectivos nomes, possuem particularidades ligadas à identidade do lugar.

\section{CONSIDERAÇÕES FINAIS}

Vimos que os espaços da cidade evidenciados na obra Mãos de Cavalo, de Daniel Galera têm um significado salutar para a memória do lugar, o que nos levou a constatar a relevância dos afetos construídos em torno de espaços de vivência individuais e coletivas.

Percebemos que os espaços da cidade de Porto Alegre evidenciados na obra são rememorados pelo protagonista, colocando em cena espaços do seu convívio com colegas de infância e também de vivências na vida adulta na companhia da esposa. Espaços de vivência coletiva também têm relevância na obra, como a Rua do Canteiro, Avenida Guaíba, Rua da Sombra, Rua Quintino Bocaiuva, Avenida Dr. Nilo Peçanha, Avenida Carlos Gomes, Via Terceira Perimetral, dentre outros, cuja cartografia da cidade ressignifica memórias do lugar.

Assim, os lugares guardam referências, sendo capazes de impactar vidas. Os nomes antigos dos logradouros de Porto Alegre possuem grande importância na obra Mãos de Cavalo, pois comportam memórias, ao passo que se mantêm no imaginário coletivo.

Os espaços evocados registram marcas particulares, além de constituírem registros de histórias e memórias dos habitantes do lugar. Assim, a obra possibilitou compreender os significados que uma cidade comporta, não só para os indivíduos em particular, mas também para o grupo social: cada pessoa 
tem uma relação íntima com os espaços da urbe.

Através dos lugares de vivências, o ser humano é capaz de levantar reflexões sobre o passado vivido, de modo que a memória vai ao encontro de lugares de pertencimento, confirmando o entrelace entre espaço e memória.

A experiência vivida pelo personagem central da obra Mãos de cavalo nos espaços citadinos possibilitou-nos perceber que a cidade é representada a partir da memória, contribuindo para o reconhecimento de si nos lugares de referência.

Para além disso, os espaços e seus respectivos registros na obra literária são capazes de contar a história de um lugar, de modo a contribuir para a preservação da memória citadina.

\section{URBAN EXPERIENCES AND MEMORIES IN MÃOS DE CAVALO, BY DANIEL GALERA}

ABSTRACT: Literary space is not merely an element that completes the narrative but is endowed with complexities that complete the identity of the characters as well as the meaning of a plot. The memory, in turn, takes care of storing the emotions, feelings, particularities of the characters. In view of this, the present work aims to analyze the relationship between memory and urban experience in the work Mãos de Cavalo, by the writer Daniel Galera, from the places of reference. We have as basic references the following theoretical assumptions: as far as memory is concerned, we adopt the thinking of Maurice Halbwachs (2006), Jacques LeGoff (1996), Ecléa Bosi (2003); As for space, we rely on the vision of Osmar Lins (1976) and Oliveira and Santos (2001). Thus, the interweaving between the memory of the characters of the plot and the spaces of experiences, provokes the valorization of the places of the city that keep individual and collective histories.

KEYWORDS: Memory. Spacy. Literature. Daniel Galera.

\section{REFERÊNCIAS}

BACHELARD, Gaston. A poética do espaço. São Paulo: Martins Fontes, 1993.

BARBIERI, Cláudia. Arquitetura literária: sob a composição do espaço narrativo. In: BORGES FILHO, O.; BARBOSA, S. (Orgs.). Poéticas do espaço literário. São Carlos, São Paulo: Claraluz, 2009, p. 105-126.

BERGSON, Henry. Matéria e Memória: Ensaios sobre a relação do corpo com o espírito. Trad. Paulo Neves. $2^{\mathrm{a}}$ ed. São Paulo: Martins Fontes, 1999.

BOSI, Ecléa. O tempo vivo da memória: ensaios de psicologia social. São Paulo: A teliê Editorial, 2003.

GALERA, Daniel. Mãos de Cavalo. São Paulo: Companhia das Letras, 2010. 
HALBWACHS, Maurice. A Memória Coletiva. São Paulo: Vértice , 1990.

JOSÉ, Elias. Memória, cultura e literatura: o prazer de ler e recriar o mundo. $1^{\underline{a}}$ ed. São Paulo: Paulus, 2012.

LINS, Osmar. Lima Barreto e o Espaço Romanesco. São Paulo: Ática. 1976

SANTOS, Luís Alberto Brandão; OLIVEIRA, Silvana Pessoa de. Sujeito, Tempo e Espaços Ficcionais: introdução à teoria da literatura. São Paulo: Martins Fontes, 2001.

SANTOS, Milton. Técnica, Espaço e Tempo: Globalização em Meio - Técnico Científico - Informacional. São Paulo: Huatea, 1994.

SANTOS, Silvana Maria dos Pantoja dos. Literatura e Memória Entre os Labirintos da Cidade: Representações na Poética de Ferreira Gullar e H. Dobal. São Luís: Editora UEMA, 2015. 